\title{
Human respiratory syncytial virus in children hospitalized for acute lower respiratory infection
}

\author{
João B. Salomão Junior, ${ }^{1}$ Luiz G. A. Gardinassi, ${ }^{2}$ Paulo V. M. Simas, ${ }^{3}$ \\ Cintia O. Bittar, ${ }^{4}$ Fátima P. Souza, ${ }^{5}$ Paula Rahal, ${ }^{6}$ Dirce M. T. Zanetta7
}

\begin{abstract}
Objective: To evaluate the prevalence and seasonality of human respiratory syncytial virus (HRSV) in children aged 0 to 6 years, hospitalized with acute lower respiratory infection (ALRI) in São José do Rio Preto, SP, Brazil, and the association between age, diagnosis, and HRSV.

Methods: Between May 2004 and September 2005, we studied 290 consecutive episodes of community-acquired ALRI in children aged 0 to 6 years admitted to the Hospital de Base of São José do Rio Preto. In order to detect HRSV, nasopharyngeal secretion samples were collected and RT-PCR molecular analysis was performed.

Results: The HRSV prevalence was $29.3 \%$ for the cases of hospitalized patients with ALRI. ALRI was common in infants (median age $=13.5$ months). HRSV was more frequent in cases of bronchiolitis $(64 \%)$ and during the first year of life (35\%). Episodes of HRSV infection occurred between fall and spring, showing higher frequency in 2004 than in 2005. Clinical and radiological criteria were not sufficient to establish the diagnosis of infection with HRSV. Antibiotic therapy was used in $78.8 \%$ of episodes of HRSV.

Conclusions: There was a high prevalence of HRSV in children aged 0 to 6 years who were hospitalized for ALRI, predominantly in younger patients or those with bronchiolitis. The circulation of the virus varied in the two years studied. Our results suggest the need for laboratory diagnosis of HRSV in the clinical practice.
\end{abstract}

J Pediatr (Rio J). 2011;87(3):219-224: Respiratory infections, human respiratory syncytial virus, hospitalized children, bronchiolitis.

\section{Introduction}

Acute lower respiratory infections (ALRIs) are characterized by acute inflammatory processes, either infectious or not, affecting alveoli, bronchioles, bronchi, and interstitial space. ${ }^{1}$ These diseases are responsible for high morbidity and mortality rates among children worldwide. ${ }^{2,3}$
Data from the Pan American Health Organization (PAHO) and the World Health Organization (WHO) on the prevalence and incidence of acute respiratory infections in Latin America show that they are responsible for 40 to $60 \%$ of all pediatric outpatient medical visits. ${ }^{4,5}$ According to the WHO, about

1. Doutor. Faculdade de Medicina de São José do Rio Preto (FAMERP), SP, Brazil.

2. Mestre. Instituto de Biociências, Letras e Ciências Exatas (IBILCE), Universidade Estadual Paulista (UNESP), São José do Rio Preto, SP, Brazil.

3. Mestre, Microbiologia. IBILCE, UNESP, São José do Rio Preto, SP, Brazil.

4. Mestre. IBILCE, UNESP, São José do Rio Preto, SP, Brazil.

5. Professora, IBILCE, UNESP, São José do Rio Preto, SP, Brazil.

6. Professora livre-docente, IBILCE, UNESP, São José do Rio Preto, SP, Brazil.

7. Professora livre-docente, FAMERP, São José do Rio Preto, SP, Brazil. Faculdade de Saúde Pública (FSP), Universidade de São Paulo (USP), São Paulo, SP, Brazil.

No conflicts of interest declared concerning the publication of this article.

Financial support: Fundação de Amparo à Pesquisa do Estado de São Paulo (FAPESP - process no. 04/06883-2).

Suggested citation: Salomão Junior JB, Gardinassi LG, Simas PV, Bittar CO, Souza FP, Rahal P, et al. Human respiratory syncytial virus in children hospitalized for acute lower respiratory infection. J Pediatr (Rio J). 2011;87(3):219-224.

Manuscript received Sep 25 2009, accepted for publication Jan 192011.

doi:10.2223/JPED.2085 
4 million children under 5 years die from ALRI every year. Furthermore, these diseases produce high direct and indirect costs with health care. ${ }^{6}$

Among the various etiologic agents causing ALRI, viruses are responsible for bronchiolitis and pneumonia, especially in children under 1 year.7,8 The main pathogen of these diseases in children is the human respiratory syncytial virus (HRSV), which has a worldwide distribution.7,8 Primarily, the infection with this virus affects children younger than 2 years, with the peak incidence from 2 to 6 months. At 2 years, approximately $95 \%$ of children have been infected with HRSV. ${ }^{9}$

In tropical regions, the HRSV epidemics begin in the fall and go through spring. In Brazil, HRSV is prevalent in the fall and winter, particularly from April to August/September each year. ${ }^{11}$ Yusuf et al., ${ }^{12}$ studying the occurrence of HRSV in nine different cities around the world, found an increased occurrence of infection with this virus in a range of relative air humidity between $45-65 \%$.

The objectives of the present study were to assess the prevalence and seasonality of HRSV in children aged 0 to 6 years hospitalized for ALRI in São José do Rio Preto, state of São Paulo, Brazil, and the association between age, diagnosis, and this viral agent.

\section{Methods}

\section{Target population and diagnostic criteria}

This is a prospective consecutive case series study conducted to assess the prevalence of HRSV in the ALRIs of children admitted to the Hospital de Base (HB) of São José do Rio Preto, a teaching hospital that provides secondary and tertiary care to the population of this municipality and the northwest region of the state of São Paulo. The study was conducted from May 1st, 2004 to September 30th, 2005. Patients were included in the study after their parents signed the written consent form. The present research project was approved by the Research Ethics Committee of the Faculdade de Medicina de São José do Rio Preto (FAMERP) (process number 062/2001).

During the study period, there were daily visits to the ward, emergency room, and pediatric intensive care unit where children are hospitalized in the HB. All children aged 0 to 6 years with community-acquired ALRI, hospitalized and who were asymptomatic for a period of at least 7 days before the onset of the symptoms were included in the study. ${ }^{13}$ ALRI was characterized by single or combined occurrence of the following physical signs and symptoms: cough, tachypnea, chest retractions, snoring, wheezing, crackling or abnormalities on chest $X$ ray. ${ }^{13}$ Chest $X$ rays were performed on the anteroposterior and lateral positions at the Department of Radiology of the HB, being evaluated by radiologists of the institution. Daily clinical follow-up of the children was conducted by Dr. João Batista Salomão Junior, head of the Department of Child Pulmonology of the HB. ALRIs were classified as isolated pneumonia, pneumonia with pleural effusion, bronchiolitis and acute wheezing according to the diagnostic recommendations of the PAHO/WHO. $5,13,14$

Pneumonia was diagnosed in children with cough, tachypnea and intercostal retractions, as well as lung auscultation showing snoring and crackling and chest $X$ ray evidencing segmental or lobar opacity. The most extensive cases of pneumonia accompanied by toxemia and pleural effusion on the $X$ ray were classified as pneumonia with pleural effusion. The diagnosis of bronchiolitis was established in children younger than 2 years who presented with tachypnea, bilateral wheezing, with no similar history and whose chest $X$ ray showed signs of diffuse pulmonary hyperinflation with or without atelectasis. For the diagnosis of acute wheezing, the following symptoms were considered: cough, snoring and expiratory wheezing in children up to 6 years old, $X$ ray evidencing hyperinflation, peribronchial or normal interstitial lesion.

The respiratory rate to establish the diagnosis (tachypnea) was adjusted for age ${ }^{14}$ : $60 \mathrm{bpm}$ or higher for children younger than 2 months; $50 \mathrm{bpm}$ or higher for children from 2 to 12 months; $40 \mathrm{bpm}$ or higher for children older than 12 months.

\section{Data collection}

We collected information on children's history, socioeconomic status, clinical signs, and diagnosis on admission

The clinical picture was followed up daily until hospital discharge. Therapeutic procedures were not predetermined, being used according to the clinical and radiographic parameters of each case.

\section{Sample collection}

The collection of nasopharyngeal secretions was done using a swab and a neonatal suction catheter after thinning with $1 \mathrm{~mL}$ of phosphate buffered saline (PBS, $\mathrm{pH}$ 7.2). The collection was carried out after the child received initial care in the morning, from Monday through Friday. The sample was collected on Mondays from those patients hospitalized over the weekend. The material was placed in a labeled vial, packed in coolers with ice, and taken to the laboratory for the processing of the samples within 1 hour.

\section{Sample processing and analysis}

The biological material was processed in the laboratory immediately after its arrival. The aspirates were divided into aliquots containing $750 \mu \mathrm{L}$ of Trizol-LS (Gibco ${ }^{\circledR}$, Invitrogen/ Gibco, Carlsbad, CA, USA) and stored in ultra-freezer until 
the analysis. RNA extraction was performed according to the manufacturer's instructions.

A High-Capacity cDNA Archive kit (Applied Biosystems ${ }^{\circledR}$, Invitrogen/Gibco, Carlsbad, CA, USA) was used to obtain the cDNA, according to the manufacturer's instructions.

The identification of HRSV was performed by nested-PCR using the primers shown in Table 1. After identification of the virus in the clinical samples, these samples were cultured in HEP-2 cell strain with intervals of 7, 14 and 21 days. Next, the technique was performed again to identify the virus.

\section{Statistical analysis}

Data analysis was carried out using the Statistical Package for the Social Sciences (SPSS), version 15.0 (SPSS Inc., Chicago, USA). The results are expressed as percentage or median, showing minimum and maximum values. Monthly prevalence rates of HRSV were calculated in the episodes of ALRI in hospitalized children. Comparisons were made using the Fischer's exact test, chi-square test or Mann-Whitney test, as appropriate, considering a significance level of $p \leq 0.05$.

\section{Results}

\section{Episodes of hospitalization for ALRI}

During the study period, from May 1st, 2004 to September 30th, 2005, there were 58,485 admissions to the Hospital de Base, with 5,320 (9.1\%) hospitalizations of children between 0-6 years. Among these hospitalizations, those identified with respiratory diseases accounted for 1,431 admissions (26.9\% of hospitalizations of children), and 303 episodes of ALRI (21.2\% of hospitalizations for respiratory disease in children).

There was no refusal from parents or guardians regarding their children's participation in the study. Of the 303 episodes of ALRI, 290 were prospectively analyzed because there was loss of 13 samples of nasopharyngeal secretion during transportation to the laboratory (four in December 2004, four in January 2005, four in February 2005, and one in March 2005). These episodes occurred in 278 children, since 10 children were hospitalized twice and one child had three hospitalizations for ALRI during the study period. None of the children had a new infection in one month, which was the period used to calculate the prevalence rates of HRSV.

In terms of age, 134 patients were infants (48.2\%), 64 were children from 13 to 24 months $(23.0 \%)$ and 80 were older than 24 months (28.8\%). In hospitalizations for ALRI studied, 274 (94.5\%) occurred in the hospital ward, $14(4.8 \%)$ in emergency room, and only two cases in the intensive care unit $(0.7 \%)$. The median hospital stay was 5 days (minimum $=1$ and maximum $=62$ ).

The reasons for hospitalization were isolated pneumonia in $48.6 \%(n=141)$ of cases, pneumonia with pleural effusion in $10.7 \%(n=31)$, bronchiolitis in $17.2 \%(n=50)$, and children with acute wheezing in $23.4 \%(n=68)$.

In the course of the disease, there was one death of a 3-month-old infant hospitalized with pneumonia and congenital heart disease, who developed respiratory failure, renal failure, septic shock, and cardiac arrest after 2 months of hospitalization. HRSV was not detected in this child.

Hospitalizations for ALRI were more frequent between June and November 2004 (winter and spring months) as shown in Figure 1. In 2005, there were no admissions for ALRI in January and only one child was hospitalized in February. Hospitalizations occurred mainly from March on, declining in September, last month of the study.

\section{Episodes of infection with ALRI}

Of the 290 episodes analyzed, the prevalence of HRSV was $29.3 \%(n=85), 54$ episodes in $2004(43.9 \%$ of 123 episodes in that year) and 31 in 2005 (18.6\% of 167 episodes in that year). One child had two episodes in which the virus was detected; the first hospitalization was in March and the second one was in August 2005. All children infected with HRSV were admitted in the ward of the Hospital de Base.

During all months with episodes of ALRI, we found the presence of HRSV, except in February 2005, with only one episode of ALRI that was negative for HRSV. The HRSV episodes occurred mainly in the winter and spring 2004 and fall 2005.

Table 1 - Primers used in PCR

\begin{tabular}{lccc}
\hline Primer & Position & Sequence (5'-3') & Reference \\
\hline GAB $(+)$ & $504-524$, protein G & YCAYTTTGAAGTGTTCAACTT & Peret et al. ${ }^{15}$ \\
F1AB $(-)$ & $3-22$, protein G & CAACTCCATTGTTATTTGCC & Peret et al. 16 \\
FV $(-)$ & $163-186$, protein F & GTTATGACACTGGTATACCAACC & Zheng et al. ${ }^{17}$
\end{tabular}


No. of hospitalizations

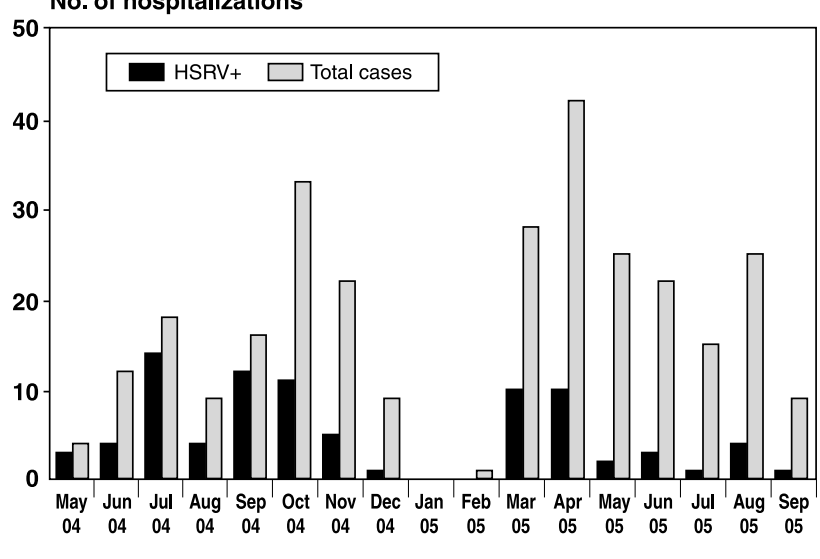

HRSV = human respiratory syncytial virus.

Figure 1 - Total number of episodes of acute lower respiratory infections and episodes with human respiratory syncytial virus (HRSV) per month in children admitted to the Hospital de Base between May 2004 and September 2005

HRSV was detected in $35.0 \%$ of 165 episodes in children aged $0-11$ months of life; in $20.9 \%$ of 79 episodes in children from 13 to 24 months; and in $26.3 \%$ of 48 episodes in children older than 24 months (Table 2). Regarding the diagnosis, HRSV was positive in $24.1 \%$ of 141 episodes of pneumonia, $25.8 \%$ of 31 cases of pneumonia with pleural effusion, $64.0 \%$ of 50 cases of bronchiolitis, and $16.2 \%$ of 68 cases with acute wheezing. In the cases of pneumonia, virus prevalence was similar in the different age groups studied. In bronchiolitis, which occurred primarily among children in the first year of life, HRSV was diagnosed in $62.5 \%$ of cases in this age group. In children with acute wheezing, there was an increase in the prevalence of HRSV as children grow older ( $p=0.048)$.

Analysis of the signals present in episodes of ALRI showed that the most frequent were cough (93.1\%), fever
(91.0\%), and coryza (62.1\%). Nasal obstruction was present in about $50 \%$ of the patients and sneezing was detected in approximately $1 / 3$ of the episodes. During the hospital stay, most children had good general health state (77.2\%). Cough was the only sign that was statistically associated with HRSV infection, although the difference was not clinically significant (88.2 vs. $95.4 \%$ of cough episodes with and without infection with HRSV, respectively).

During hospital stay, shortness of breath (72.4\%) and wheezing $(71.0 \%)$ were the most common clinical pulmonary manifestations shown by the patients with ALRI. Rales and wheezing were present in about half of the hospitalized children. There was a significant positive association between infection with HRSV and occurrence of intercostal retractions ( $p=0.03$ ).

Regarding the use of antibiotics, about half $(52.1 \%)$ of the children used antibiotics before hospital admission and $78.3 \%$ during hospitalization. In episodes with HRSV infection, $78.8 \%$ received antibiotics during hospitalization.

\section{Discussion}

In the present study we investigated the prevalence and seasonality of HRSV in children aged 0 to 6 years hospitalized for ALRI in São José do Rio Preto, state of São Paulo, Brazil, and the association between age, diagnosis, and this viral agent.

This study assessed $96 \%$ of all cases of ALRI in children who required hospitalization during the study period in a tertiary referral hospital offering health care to a population of approximately 1 million people. In the 290 episodes of ALRI we evaluated, the prevalence of HRSV was $29.3 \%$. Costa et al., 18 evaluating 379 episodes of ALRI in children younger than 5 years old hospitalized in Uberlândia, state of Minas Gerais, Brazil, found HRSV-positive results in $26.4 \%$ of cases.

Table 2 - Prevalence of human respiratory syncytial virus by age group among all children and for diagnosis of episodes of acute lower respiratory infection in children admitted to Base Hospital between May 2004 and September 2005 in São José do Rio Preto, Brazil

\begin{tabular}{|c|c|c|c|c|c|c|}
\hline \multirow[b]{2}{*}{ Age (months) } & \multicolumn{3}{|c|}{ Number of episodes } & \multicolumn{3}{|c|}{ HRSV prevalence (\%) } \\
\hline & 0 to 12 & 13 to 24 & Older than 24 & 0 to 12 & 13 to 24 & Older than 24 \\
\hline Pneumonia & 63 & 36 & 42 & 25.4 & 19.4 & 26.2 \\
\hline Pneumonia with pleural effusion & 3 & 12 & 16 & $*$ & 25 & 18.8 \\
\hline Bronchiolitis & 48 & 2 & 0 & 62.5 & $*$ & . \\
\hline Acute wheezing & 29 & 17 & 22 & 6.9 & 11.8 & 31.8 \\
\hline Total & 143 & 67 & 80 & 35 & 20.9 & 26.3 \\
\hline
\end{tabular}

HRSV = human respiratory syncytial virus.

* Prevalence cannot be estimated due to the small number or absence of episodes. 
Several studies have shown that HRSV is a frequent cause of acute respiratory infections in children under 5 years, reaching 21 to $68 \%$ of the cases investigated. ${ }^{18-20}$ This wide variation can be explained considering the following aspects: different methodologies used to establish the diagnosis, study site, diseases studied, duration of the study, period of the year, age of the patients included, number of samples, health care and hospitalization setting.

The percentage of viral identification in children with ALRI is associated with clinical picture. ${ }^{21}$ The HRSV was found in $24 \%$ of cases of pneumonia and $26 \%$ of pneumonia with pleural effusion. Most studies of HRSV in ALRI do not differentiate pneumonia with pleural effusion. However, a study of hospitalized children with ALRI showed that the HRSV prevalence was lower in hospitalized children who had pleural effusion than in those who had pneumonia without this complication, ${ }^{22}$ contradicting the findings of the present study. Although it can occur in viral pneumonia, pleural effusion has been more frequently found in cases of bacterial infection. ${ }^{23}$ The technique used to detect viral infection in the present study included cell culture, which is safe to determine current viral infections. However, since the detection of other infectious agents was not the objective of our study, it is not possible to exclude the possibility that these cases had co-infection with other infectious agents.

The high frequency of infection with HRSV in children with bronchiolitis in the present study is consistent with the literature. 7,8

The study period, from May 2004 to September 2005, covered two winters, part of two falls, one spring and one summer. Our study began when the episodes of ALRI in the hospitalized children began to occur in 2004 and lasted until there was a significant decrease in the number of episodes in 2005 . The study was discontinued after 10 days without hospitalization for ALRI. The analysis of results, considering the prevalence of HRSV for each month, enabled us to evaluate the presence of seasonality.

HRSV infections occurred from fall to spring, as it has been described in the literature, 3,7,9 with peaks in March and April, similar to that observed in Ribeirão Preto, state of São Paulo, by Cintra et al., ${ }^{19}$ and in Uberlândia, state of Minas Gerais, by Costa et al. ${ }^{18}$ Furthermore, the prevalence of HRSV in children hospitalized for ALRI was higher in 2004 than in 2005, even when comparing only the same months in both years, suggesting that the viral circulation varied between these years. Investigating the presence of groups A and B of HRSV in a period of 7 years in Porto Alegre, state of Rio Grande do Sul, Straliotto et al. ${ }^{24}$ found circulation of this virus in the community throughout the year, including summer.

Clinical data were not correlated with the presence of HRSV infection in the present study, except for intercostal retractions and coughing; however, even these associations were not clinically relevant.
In children with wheezing, there was a lower prevalence of HRSV positive results than in the other diagnoses considered. There was an increase in the prevalence in older children. In the literature, although HRSV in children with wheezing is common, this clinical sign was not sufficient for the identification of HRSV infection. ${ }^{25}$ Bronchiolitis occurred almost exclusively in children under 1 year and was diagnosed with a higher prevalence of HRSV infection.

In cases of pneumonia, the prevalence of HRSV infection was similar in the age groups studied. This finding is in disagreement with the literature, which describes HRSV infection associated with pneumonia in children younger than 2 years. ${ }^{9,26}$ In the present study, our results showed higher frequency of HRSV infection in children under 1 year, suggesting that they are more susceptible to HRSV, as it has been previously reported. 27

The present study showed that the clinical and radiological criteria were not sufficient to identify the etiology of the HRSV infection. Children received antibiotics very often both before and during hospitalization, and such procedure was similar in the groups with and without HRSV infection.

The primary objective of the present study was to estimate the prevalence of HRSV as the etiologic agent of ALRI in this population and we did not interfere with the patients' treatment. The laboratory tests for identification of HRSV were performed after the collection of all samples at the end of the study and were not available upon hospital admission. Therefore, the high frequency of antibiotic use observed in our study corresponded to use in the daily clinical practice, with uncontrolled use of this kind of medication. 3,28,29 The results show the need for a diagnostic based on laboratory tests to identify HRSV infection in the clinical practice. HRSV is a frequent agent in ALRIs and its diagnosis can prevent the inappropriate use of antibiotics, which can cause bacterial superinfection in children with viral infections, originating resistant forms of bacteria, increasing the occurrence of side effects and treatment costs. 28,29

The laboratory identification of the virus can directly influence the suspension of prescription of antibiotics for these patients. In a hospital in Cordoba, Argentina, the frequency of initial prescription of antibiotics for patients hospitalized with pneumonia caused by HRSV did not change after the implementation of routine laboratory technique for diagnosis of this virus, but there was a significant increase in its suspension after the confirmation of the etiology. ${ }^{30}$

The techniques available for the laboratory diagnosis (immunofluorescence and molecular techniques), which used to be expensive and time consuming, restricted to research laboratories, currently are available in clinical laboratories at a lower cost and can be included in clinical routine. Despite their higher cost, molecular techniques to detect viral agents are the most sensitive and specific for diagnosis than direct immunofluorescence with monoclonal 
antibodies $^{31}$ and make it possible to identify viral strains in the population.

The potential limitation of the present study is the fact that we evaluated only children with more severe ALRI who required hospitalization in a tertiary hospital. The results showed different prevalence rates of the virus in 2004 and 2005, even when comparing the same months of followup in both years. Further studies, which are broader and longer, involving other hospitals and medical centers of varying complexities are needed to better characterize the clinical and epidemiological aspects of HRSV infections in the geographical area studied, as well as the role of HRSV in milder cases of ALRI. Although the results show high frequency of antibiotic use in children infected with HRSV, the performance of laboratory tests at the end of our study did not allow to assess the impact of the diagnosis of viral infection on the frequency of antibiotic prescriptions.

In conclusion, the present study contributes to establish the prevalence of HRSV in children hospitalized for ALRI and suggests the need for an accurate and sensitive diagnosis, enabling a more appropriate treatment of these infections.

\section{References}

1. Hilman BC. Clinical assessment of pulmonary disease in infants and children. In: Hilman BC (editor). Pediatric respiratory disease: diagnosis and treatment. Philadelphia: WB Saunders Company; 1993. p. 57-67.

2. World Health Organization. Management of childhood illness. Geneva: WHO; 1995.

3. Chidgey SM, Broadley KJ. Respiratory syncytial virus infections: characteristics and treatment. J Pharm Pharmacol. 2005; 57:13711381.4 .

4. Brasil. Ministério da Saúde. Manual de normas para infecção respiratória aguda. Brasília: Sociedades Brasileiras de Pediatria e Pneumologia; 1991.

5. Pan American Health Organization, World Health Organization. Respiratory infections in children. Washington: PAHO/WHO; 1999.

6. Brasil. Ministério da Saúde. DATASUS; 2006. http://www. datasus. gov.br. Access: 06 Jul 2007.

7. Guthrie EW. Common pediatric respiratory illnesses. US Pharm. 2005;7:2-8.

8. Weissembacher MC, Ávila MM. Os vírus como causa de IRA alta e baixa em crianças: características gerais e diagnóstico. In: Benguigui Y, Schmunis G, Yunes J (editores). Infecções respiratórias em crianças. Washington: Organização Pan-Americana da Saúde; 1998. p. 91-103

9. Collins $\mathrm{CL}$, Pollard AJ. Respiratory syncytial virus infections in children and adults. J Infect. 2002;45:10-7.

10. Santos NS, Ramanos MT, Wigg MD. Introdução à virologia humana. Rio de Janeiro: Guanabara Koogan; 2002.

11. Bricks LF. Prevention of respiratory syncytial virus infections. Rev Hosp Clin Fac Med Sao Paulo. 2001;56:79-90.

12. Yusuf S, Piedimonte G, Auais A, Demmler G, Krishnan S, Van Caeseele $\mathrm{P}$, et al. The relationship of meteorological conditions to the epidemic activity of respiratory syncytial virus. Epidemiol Infect. 2007;135:1077-90.

13. World Health Organization. Handbook: IMCI integrated management of childhood illness. Geneva: WHO; 2000.
14. Simpson W, Hacking PM, Court SD, Gardner PS. The radiological findings in respiratory syncytial virus infection in children. Part II. The correlation of radiological categories with clinical and virological findings. Pediatr Radiol. 1974;2:155-60.

15. Peret TC, Hall CB, Schnabel KC, Golub JA, Anderson LJ. Circulation patterns of genetically distinct group $A$ and $B$ strains of human respiratory syncytial virus in a community. J Gen Virol. 1998;79:2221-9.

16. Peret TC, Hall CB, Hammond GW, Piedra PA, Storch GA, Sullender $W M$, et al. Circulation patterns of group $A$ and $B$ human respiratory syncytial virus genotypes in 5 communities in North America. J Infect Dis. 2000;181:1891-6.

17. Zheng H, Peret TC, Randolph VB, Crowley JC, Anderson LJ. Strainspecific reverse transcriptase PCR assay: means to distinguish candidate vaccine from wild-type strains of respiratory syncytial virus. J Clin Microbiol 1996;34:334-7.

18. Costa LF, Yokosawa J, Mantese OC, Oliveira TF, Silveira HL, Nepomuceno LL, et al. Respiratory viruses in children younger than five years old with acute respiratory disease from 2001 to 2004 in Uberlândia, MG, Brazil. Mem Inst Oswaldo Cruz. 2006;101:301-6.

19. Cintra OA, Owa MA, Machado AA, Cervi MC, Figueiredo LT, Rocha $G M$, et al. Occurrence and severity of infections caused by subgroup $A$ and $B$ respiratory syncytial virus in children in southeast Brazil. J Med Virol. 2001;65:408-12.

20. Thomazelli LM, Vieira S, Leal AL, Souza TS, Oliveira DB, Golono $M A$, et al. Surveillance of eight respiratory viruses in clinical samples of pediatric patients in southeast Brazil. J Pediatr (Rio J). $2007 ; 83: 422-8$

21. Jeng MJ, Lemen RJ. Respiratory syncytial virus bronchiolitis. Am Fam Physician. 1997;55:1139-46.

22. Miyao CR, Gilio AE, Vieira $S$, Hein N, Pahl MM, Betta SL, et al. Infecções virais em crianças internadas por doença aguda do trato respiratório inferior. J Pediatr (Rio J). 1999;75:334-44.

23. Sandora TJ, Harper MB. Pneumonia in hospitalized children. Pediatr Clin N Am. 2005; 52:1059-81.

24. Straliotto SM, Nestor SM, Siqueira MM. Respiratory syncytial virus groups A and B in Porto Alegre, Brazil, from 1990 to 1995 and 1998. Mem Inst Oswaldo Cruz. 2001;96:155-8.

25. Kabra SK, Broor S, Lodha R, Maitreyi RS, Ghosh M. Can we identify acute severe viral lower respiratory tract infection clinically? Indian Pediatr. 2004;41:245-9.

26. Malhotra A, Krilov LR. Influenza and respiratory syncytial virus: update on infection, management, and prevention. Pediatr Clin North Am. 2000;47:353-72, vi-vii.

27. Queiroz DA, Duringon EL, Botosso VF, Ejzemberg B, Vieira SE, Mineo $\mathrm{JR}$, et al. Immune response to respiratory syncytial virus in young Brazilian children. Braz J Med Biol Res. 2002;35:1183-93.

28. Spurling GK, Fonseka K, Doust J, Del Mar C. Antibiotics for brochiolitis in children. Cochrane Database Syst Rev. 2007;1: CD005189.

29. D'Elia C, Siqueira MM, Portes SA, Sant'Anna CC. Infecções do trato respiratório inferior pelo vírus sincicial respiratório em crianças hospitalizadas menores de um ano de idade. Rev Soc Bras Med Trop. 2005;38:7-10.

30. Collard Borsotti MV, Moreno LB, Bujedo E, Marqués I, Mosca L, Ferreira Soaje $\mathrm{P}$, et al. Prescripción de antibióticos en lactantes hospitalizados con neumonía por virus sincicial respiratorio. Arch Argent Pediatr. 2008;106:515-7.

31. Reis AD, Fink MC, Machado CM, Paz Jde P Jr, Oliveira RR, Tateno $A F$, et al. Comparison of direct immunofluorescence, conventional cell culture and polymerase chain reaction techniques for detecting respiratory syncytial virus in nasopharyngeal aspirates from infants. Rev Inst Med Trop Sao Paulo. 2008;50:37-40.

Correspondence:

Dirce Maria Trevisan Zanetta

Av. Dr. Arnaldo, 715

CEP 01246-904 - São Paulo, SP - Brazil

Tel.: +55 (11) 3061.7110, +55 (11) 3061.7710

Fax: +55 (11) 3061.7926

E-mail: dzanetta@usp.br 